\title{
Nosocomial valve endocarditis due to corynebacterium striatum: a
}

\section{case report}

\author{
Jorge Marull1,3,4 and Pablo A Casares*2,3,4
}

\author{
Address: 1515 59th St. Apt 25C 25th FL, zip 10019, New York, NY, USA, 210 Amsterdam Ave. Apt 306, zip 10023, New York, NY, USA, \\ ${ }^{3}$ Department of Medicine, St Luke's Roosevelt Hospital Center, Columbia University College of Physicians and Surgeons, New York, NY, USA and \\ ${ }^{4}$ St. Luke's Roosevelt Hospital Center, Amsterdam Ave \& W 113th St New York, NY 10025, USA \\ Email: Jorge Marull - jmarull@chpnet.org; Pablo A Casares* - pcasares@chpnet.org \\ * Corresponding author
}

Published: 12 December 2008

Cases Journal 2008, 1:388 doi:10.1186/1757-1626-1-388

This article is available from: http://www.casesjournal.com/content/l/I/388

(C) 2008 Marull and Casares; licensee BioMed Central Ltd.

This is an Open Access article distributed under the terms of the Creative Commons Attribution License (http://creativecommons.org/licenses/by/2.0), which permits unrestricted use, distribution, and reproduction in any medium, provided the original work is properly cited.
Received: I September 2008

Accepted: 12 December 2008

\begin{abstract}
Staphylococcus aureus, Coagulase-negative staphylococci, and Enterococci sp. are the usual pathogens involved in nosocomial bacterial endocarditis. Corynebacterium species isolation in blood specimens is usually considered to be a contaminant. We present an interesting case of native mitral valve endocarditis in a 73 year old African American female that was diagnosed days after she was discharged from our institution. The infection was cleared with medical therapy alone.
\end{abstract}

\section{Introduction}

Over the past twenty years, the epidemiological profile of infective endocarditis has been changing. [1] The number of cases of hospital-acquired endocarditis has been increasing. This entity carries a higher mortality rate compared with community-acquired cases. Indwelling catheters, intravenous lines, intravascular procedures and devices have increased the risk of bacteriemia. [2] The presentation is not always evident and especial importance should be given to the clinical history in a patient with fever and no evident source of infection. Positive blood cultures for Corynebacterium species, and Corynebacterium striatum in particular, should never be overlooked.

\section{Case report}

This is a case of a 73-year-old African American female with a history of hypertension, chronic kidney disease, diastolic congestive heart failure and diabetes mellitus who consulted to the Emergency Service with three-day history of fevers, chills and fatigue. The patient was discharged home 15 days prior to this admission after a 9- day hospitalization where she received treatment for an exacerbation of her heart failure. Vital signs on this admission: Temperature of $102.4 \mathrm{~F}$, Blood pressure of $170 / 68$ $\mathrm{mm} \mathrm{Hg}$, Heart Rate of 100 beats per minute, Respiratory Rate of 20 breaths per min., and Oxygen Saturation of $98 \%$ on 3 liters nasal canula. Physical examination revealed a new $3 / 6$ non-radiating systolic murmur at the apex. Auscultation of the lungs revealed clear breath sounds and inspection of lower extremities showed trace edema bilaterally. Basic metabolic panel and complete blood cell count was ordered (table 1). The patient was started on broad spectrum coverage with Vancomycin and Cefepime; due her previous admission, she was treated as she was having a nosocomial infection. Two sets of blood cultures drawn on admission grew CS in both the aerobic and anaerobic bottles sensitive to vancomycin (table 2). In order to distinguish CS from other Corynebacterium species, a metabolic profile obtained in the bioMerieux data base (version 2.0) was applied. Surveillance cultures were negative on day 6 . A trans-thoracic echocardiogram showed asymmetric shaggy densities on the mitral valve, suggesting possible vegetations. The Doppler study 
Table I: Basic metabolic panel and complete blood cell count

\begin{tabular}{llllll}
\hline Hematology & \multicolumn{5}{c}{ Chemistry } \\
\hline WBC & 13.300 & Sodium & 138 & ANA & negative \\
Hemoglobin & 8.3 & Potasium & 4.2 & Comp C3 & normal \\
Hematocrit & 25 & Chloride & 109 & Comp C4 & normal \\
Platelet & 334 & BUN & 65 & Hepatitis panel non-reactive & \\
& & Creatinine & 3.0 & & \\
& & Glucose & 183 & & \\
\hline
\end{tabular}

Ref: White blood count (WBC), Blood Urea Nitrogen (BUN).

revealed mild to moderate mitral regurgitation, and a normal ejection fraction alone with an abnormal diastolic compliance of the left ventricle. A similar study done on the previous admission did not reveal any foreign material or valvular damage. A subsequent trans-esophageal echocardiogram confirmed the presence of a $2.9 \times 0.5 \mathrm{~cm}$ echo densities indicating mitral valve endocarditis with possible small eccentric perforation of the valve. The patient received a six-week course of intravenous Vancomycin, dosed according to through blood levels with a target of $15-20 \mathrm{ug} / \mathrm{ml}$, and became afebrile. She recovered and was finally discharged home. Surgical repair of the mitral valve was offered, which she adamantly refused. A surveillance echocardiogram done after treatment unfortunately showed findings consistent with moderate pulmonary hypertension and a persistent mitral regurgitation.

\section{Discussion}

Two of the Duke major criteria were met, including the microbiology and echocardiographic findings, making a definitive diagnosis. [3] There is neither a recognized standard method nor specific MIC breakpoints or guidelines published by NICCS for antimicrobial testing of coryneform bacteria. National Committee for Clinical Laboratory Standards interpretive criteria currently valid for staphylococci, streptococci, or listeria monocytogenes was applied. Chester in 1901 and then Eberson in 1918 described for the first time the Striatum strain, and since then numerous corynebacterium species have been identified and reclassified, in different strains. [4]

Table 2: Antibiotic resistance profile

\begin{tabular}{ll}
\hline Ampicillin & $>4 \mathrm{R}$ \\
Azithromycin & $>2 \mathrm{R}$ \\
Cefepime & $>2 \mathrm{R}$ \\
Cefotaxime & $>2 \mathrm{R}$ \\
Erythromycin & $>0.5 \mathrm{R}$ \\
Meropenem & $0.5 \mathrm{~S}$ \\
Vancomycin & $0.5 \mathrm{~S}$
\end{tabular}

Ref: $S=$ SUSCEPTIBLE. $I=$ INTERMEDIATE R = RESISTANT IR = INDUCED RESISTANT.
In the 1980s and 1990s CS infections have been disregarded. It was only until recently that Corynebacterium diphtheria was considered to be the only pathogen of the coryneform species. Today, other species, such as C. jeikeium, C. urealiticum, C. amycolatum along with CS, are recognized as emerging hospital pathogens. The pathogenicity in non-diphtheriae corynebacteria species isn't well-known. Neither toxin nor other virulence factors explain the transition from colonization to infection. [5] Martin et al. isolated identical strains of CS from a leg ulcer and from the bloodstream in a patient with peripheral vascular disease, confirming the entry of the bacterium through the skin to the circulation. [6] The spectrum of diseases generated by CS is extensive, going from meningitis, keratitis, to arthritis, among others. [5]

The spread of CS from patient to patient and nosocomial outbreaks have been documented. Leonard et al., Iaria et al., and Brandenbrug described outbreaks caused by a single strain in intensive care unit settings. Leonard et al., described a selective pressure due to prior exposure to antibiotics favoring the overgrowth of CS in immune deficient patients. Brandenbrug et al recovered the strain in the air around infected patients and on the hands of the housestaff. [7-9]. Vancomycin is still the drug of choice for many authors since in vitro resistance has not been showed for this or any other Corynebacterium species. The spread of multidrug resistance strains of CS is concerning, although the mechanisms are not cleared. Ten years ago, CS was still sensitive to beta lactams, fluoroquinolones, carbapenems and linezolid. [10,11]

\section{Conclusion}

In the hospital setting, positive blood cultures for Corynebacterium species, and CS in particular, should never be overlooked. Unlike other hospital-acquired pathogens such as staphylococcal or enterococcal species, that tend to infect patients with a predisposing condition such as a valvulopathy, CS endocarditis can be seen even in patients without prosthetic valves or structural heart disease. More research needs to be conducted to evidence what resistance mechanisms are involving this organism. Nowadays CS is being considered one of the emergent nosocomial agents implicated in endocarditis and serious infections. 


\section{Consent}

Written informed consent was obtained from the patient for publication of this case report and accompanying images. A copy of the written consent is available for review by the Editor-in-Chief of this journal.

\section{Competing interests}

The authors declare that they have no competing interests.

\section{Authors' contributions}

JM was a major contributor in writing the manuscript, analyzing the data, and collecting the information in the outpatient setting. PC wrote the abstract and made a mayor contribution in the discussion and conclusion. Reviewed the article and corrected the medical terminology used. Both authors read and approved the final manuscript.

\section{References}

I. Cabell $\mathrm{CH}$, Jollis JG, et al.: Changing patient characteristics and the effect on mortality in endocarditis. Arch Intern Med 2002, I 62(I):90-4.

2. Martin-Davila $P$, Fortum J, et al.: Nosocomial endocarditis in a tertiary hospital: an increasing trend in native valve cases. Chest 2003, I 28(2):772-9.

3. Li JS, Sexton DJ, Mick N, Nettles R, Fowler VG Jr, Ryan T, Bashore T, Corey GR: Proposed modification to the Duke criteria of infective endocarditis. Clin Infect Dis 2000, 30:633-638.

4. Skerman VBD, McGowan V, Sneath PHA, (editors): Approved Lists of Bacterial Names. Med J Aust 1980, 2(I):3-4.

5. Watkins DA, Chaine A, Creger RJ, Jacobs MR, Lazarus HM: Corynebacterium Striatum: a Diphteroid with pathogenic potential. Clin Infect Dis 1993, 17:21-5.

6. Martin MC, Melon O, Celada MM, Alvarez J, Mendez FJ, Vazquez F: Septicaemia due to Corynebacterium striatum: molecular confirmation of entry via the skin. J Med Microbiol 2003, 52(Pt 7):599-602.

7. Leonard RB, Nowowiejski DJ, Warren JJ, Finn DJ, Coyle MB: Molecular evidence of person-to-person transmission of pigmented strain of Corynebacterium striatum in intensive care units. J Clin Microbiol I994, 32(I): I64-9.

8. laria C, Stassi G, Costa GB, Biondo C, Gerace E, Noto A, Spinella SG David A, Cascio A: Outbreak of multi-resistant Corynebacterium striatum infection in an Italian general intensive care unit. J Hosp Infect 1990, 67(I):102-104.

9. Brandenburg $A H$, Van Belkum A, Van Pelt C, Bruining HA, Mouton JW, Verbrugh HA: Patient-to-patient spread of a single strain of Corynebacterium striatum causing infections in a surgical intensive care unit. J Clin Microbiol 1996, 34(9):2089-2094.

10. Otsuka Y, Ohkusu K, Kawamura Y, Baba S, Ezaki T, Kimura S: Emergence of multidrug-resistant Corynebacterium striatum as a nosocomial pathogen in a long-term hospitalized patients with underlying diseases. Diag Microbiol Infect Dis 2006, 54(2): 109-14.

II. Renom F, Garau M, Rubi M, Ramis F, Galmes A, Sorano JB: Nosocomial outbreak of Corynebacterium striatum Infection in Patients with Chonic Obstructive Pulmonary Disease. J Clin Microbiol 2007, 45(6):2064-7.
Publish with Bio Med Central and every scientist can read your work free of charge

"BioMed Central will be the most significant development for disseminating the results of biomedical research in our lifetime. "

Sir Paul Nurse, Cancer Research UK

Your research papers will be:

- available free of charge to the entire biomedical community

- peer reviewed and published immediately upon acceptance

- cited in PubMed and archived on PubMed Central

- yours - you keep the copyright

Submit your manuscript here:

http://www.biomedcentral.com/info/publishing_adv.asp
BioMedcentral 